\title{
First Things First: Foundational Requirements for a Medical Home in an Academic Medical Center
}

\author{
Jane Forman, SCD, $M H S^{7}$, Molly Harrod, $P h D^{7}$, Claire Robinson, $M P H^{7}$,

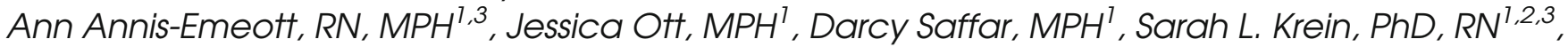 \\ and Clinton L. Greenstone, MD ${ }^{1,2}$
}

'PACT Research Inspiring Innovations and Self-Management (PRIISM) Demonstration Laboratory, Center for Clinical Management Research, VA Ann Arbor Healthcare System, Ann Arbor, MI, USA; ${ }^{2}$ Department of Internal Medicine, University of Michigan, Ann Arbor, MI, USA; ${ }^{3}$ School of Nursing, University of Michigan, Ann Arbor, MI, USA.

BACKGROUND: In 2010, the Veterans Health Administration (VHA) began implementation of its medical home, Patient Aligned Care Teams (PACT), in 900 primary care clinics nationwide, with 120 located in academically affiliated medical centers. The literature on Patient-Centered Medical Home (PCMH) implementation has focused mainly on small, nonacademic practices.

OBJECTIVE: To understand the experiences of primary care leadership, physicians and staff during early PACT implementation in a VHA academically affiliated primary care clinic and provide insights to guide future $\mathrm{PCMH}$ implementation.

DESIGN: We conducted a qualitative case study during early PACT implementation.

PARTICIPANTS: Primary care clinical leadership, primary care providers, residents, and staff.

APPROACH: Between February 2011 and March 2012, we conducted 22 semi-structured interviews, purposively sampling participants by clinic role, and convenience sampling within role. We also conducted observations of 30 nurse case manager staff meetings, and collected data on growth in the number of patients, staff, and physicians. We used a template organizing approach to data analysis, using select constructs from the Consolidated Framework for Implementation Research (CFIR).

KEY RESULTS: Establishing foundational requirements was an essential first step in implementing the PACT model, with teamlets able to do practice redesign work. Short-staffing undermined development of teamlet working relationships. Lack of co-location of teamlet members in clinic and difficulty communicating with residents when they were off-site hampered communication. Opportunities to educate and reinforce PACT principles were constrained by the limited clinic hours of part-time primary care providers and residents, and delays in teamlet formation.

CONCLUSIONS: Large academic medical centers face special challenges in implementing the medical home model. In an era of increasing emphasis on patient-centered care, our findings will inform efforts to both improve patient care and train clinicians to move from physician-centric to multidisciplinary care delivery.

Published online April 9, 2014
KEY WORDS: evaluation; primary care redesign; qualitative research; Veterans; medical home.

J Gen Intern Med 29(Suppl 2):S640-8

DOI: $10.1007 / \mathrm{s} 11606-013-2674-Z$

(c) Society of General Internal Medicine 2013

\section{BACKGROUND}

The Patient-Centered Medical Home (PCMH) model emphasizes comprehensive, coordinated, accessible, continuous, team-based, and patient-driven primary care. ${ }^{1}$ The drive to transform primary care by implementing this model is growing. ${ }^{2}$ Provisions in the Patient Protection and Affordable Care Act provide increasing motivation for healthcare entities to adopt it. ${ }^{3}$ In 2010, the Veterans Health Administration (VHA) developed agency-wide strategic goals and operational initiatives to advance implementation of the model in its over 900 primary care clinics nationwide. These initiatives build on improvements to the primary care delivery system that began in the mid1990s. ${ }^{4}$

The VHA's medical home, called Patient Aligned Care Teams (PACT), aims to strengthen patient-centered care by increasing staffing and reorganizing into small interdisciplinary teamlets. VHA has mandated that a teamlet consist of a ratio of three full-time equivalent (FTE) staff-one registered nurse case manager (RNCM), one licensed practical nurse (LPN), and one clerk - to one primary care provider (PCP) FTE. ${ }^{5}$ Responsibilities are defined so that all teamlet members perform at the top of their scope of practice $^{6-8}$ and members work closely together to deliver care to a panel of patients. In the PACT model, teamlets have an essential role in practice redesign; that is, developing and implementing work processes aimed at meeting PACT goals, such as improving patient access, care coordination, and population health management.

Approximately 150 of VHA's primary care clinics are located within medical centers. About $80 \%$ of these clinics are academically affiliated and provide care to a significant 
number of Veterans, as well as serve as clinical learning environments for residents who are increasingly expected to be trained to provide patient-centered, team-based care. ${ }^{9}$ VHA funds about $15 \%$ of U.S. internal medicine resident positions. ${ }^{10}$ Given the role VHA academic primary care clinics have in training clinicians and delivering patient care, it is crucial to understand how the academic context affects PACT implementation.

Although quantitative studies have shown that practice size, in terms of numbers of providers, is positively associated with greater presence of PCMH elements and processes, ${ }^{11-15}$ none have looked at the effect of increased numbers of staff, parttime providers, and residents on PCMH implementation in large primary care teaching clinics. To date, qualitative studies of PCMH implementation have looked primarily at small, nonacademic practices with ten or fewer physicians, ${ }^{16-19}$ and, with one exception, ${ }^{19}$ have not focused on differences by practice size. ${ }^{20-22}$ Few have assessed implementation in academic clinics. $^{23,24}$ Therefore, we conducted a qualitative case study within a large VHA academically affiliated primary care clinic to understand the experiences of primary care leadership, physicians, and staff during early PACT implementation, and to provide insights to help guide future $\mathrm{PCMH}$ implementation initiatives.

\section{METHODS}

\section{Setting}

The setting is a large VHA Midwestern, academically affiliated, rapidly growing primary care clinic within a tertiary care medical center. Many PCPs have multiple roles, including inpatient attending, staffing an urgent care clinic, teaching, mentoring residents, and conducting research, and thus have limited clinic time in primary care. About $80 \%$ work less than 2 days $(16 \mathrm{~h})$ per week in primary care. Just under one-third of physicians, approximately 30 in any given year, are medical residents who have their own patient panels, work with mentors for their 3-year tenure, and are in clinic $4 \mathrm{~h}$ per week. Residents care for approximately 3,200 primary care patients, or $15 \%$ of the 21,000 patients in the clinic. Together, 75 PCPs and residents comprise 21 physician FTE employees (FTEEs).

Since the start of PACT implementation in 2010, the primary care clinic has grown rapidly in terms of patients, providers, and staff (Table 1). Physical space in the primary care clinic is limited and not contiguous. Given the size of the clinic and that part-time providers and residents are often off-site, communication among staff, providers, and residents occurs through several modes, including the VHA electronic medical record (EMR), and university and VHA paging and e-mail systems.

\section{Sampling and Data Collection}

We conducted a qualitative case study using multiple data collection methods, including interviews with providers, residents, and staff; and observations of weekly RNCM staff meetings. From February 2011 to March 2012, the first three authors and two additional interviewers, in pairs, conducted semi-structured face-toface interviews with primary care personnel, including leadership (Ambulatory and Primary Care clinic leaders responsible for PACT implementation), PCPs, residents, RNCMs, LPNs, and clerks. Participants were purposively sampled by teamlet role, and convenience sampled within role. ${ }^{25}$ To recruit participants, members of the research team made formal presentations about the study in primary care staff meetings and sent e-mail invitations to potential participants. We scheduled and conducted interviews with the 22 participants who responded (Table 2). Interviews covered three primary domains: knowledge of PACT, communication, and implementation challenges (Box 1).

Table 1. Clinic Growth, Data Collection, and PACT Implementation Milestones, 2010-2013

\begin{tabular}{|c|c|c|c|c|c|}
\hline & 2010 & 2011 & 2012 & 2013 & \% Increase (2010-2013) \\
\hline \multicolumn{6}{|l|}{ Clinic growth* } \\
\hline Patients & 14,803 & 16,148 & 18,340 & 21,024 & $42 \%$ \\
\hline Non-physician staff & 23 & 33 & 43 & 52 & $126 \%$ \\
\hline Physicians & 62 & 69 & 70 & 75 & $21 \%$ \\
\hline Primary care providers & 35 & 37 & 36 & 45 & $28 \%$ \\
\hline Residents & 27 & 32 & 34 & 30 & $11 \%$ \\
\hline Physician FTEE & 15 & 18 & 19 & 21 & $40 \%$ \\
\hline Staffing ratio ( $3: 1$ mandated $)$ & 1.53 & 1.83 & 2.26 & 2.48 & \\
\hline \multicolumn{6}{|l|}{ PACT milestones } \\
\hline Funding received & April & & & & \\
\hline Study data collection & & Begin: February & End: March & & \\
\hline Teamlets assigned & & May & & & \\
\hline Teamlets engaged in practice redesign & & & & January & \\
\hline
\end{tabular}

${ }^{*}$ Clinic numbers are reported for April of each year 
Interviews were audio-recorded and transcribed verbatim. Each lasted an average of $1 \mathrm{~h}$ (range 1/2-2 h).

\section{Box 1: Primary Interview Questions}

Primary Interview Questions

- What is your role in this facility?

- What have you heard so far about PACT?

- What changes in your role and in how care is delivered in the clinic have you seen? What do you like? What should be done differently?

- Part of PACT reorganization is switching from a team to a teamlet model. PACT defines a teamlet as alignment of staff that includes one PCP FTEE, one RN, one LPN, and one Clerk who work together on a panel of patients. Do you consider yourself a member of a teamlet?

- Who do you communicate the most with on a day-to-day basis? Within Primary Care? Outside Primary Care?

- How do you share information with the people you work with?

- What challenges do you face in communicating with people you work with about patient care?

- How do these challenges affect patient care?

- How do you think PACT will affect the way you communicate with the people you work with? Patient care?

-What do you see as the main challenges to implementing PACT?

What do you see as the facilitators/strengths?

- What support, resources, or personnel does this clinic need to make the changes associated with PACT?

We also conducted observations of 30 weekly RNCM staff meetings (July 2011-March 2012) and documented them with handwritten field notes, which the observer typed into electronic form using Microsoft Word. Administrative data on the number of patients, staff, and physicians was also collected. We obtained informed consent from all participants interviewed and/or observed. Approval was obtained from the study site's Institutional Review Board.

\section{Data Analysis}

The data analysts (JF, MH, CR, JO) used a template organizing approach ${ }^{26}$ using select constructs from the Consolidated Framework for Implementation Research $(\mathrm{CFIR})^{27}$ to code the data. The CFIR is a comprehensive taxonomy of common constructs from published implementation theories and frameworks that may influence implementation success. A subset of constructs is typically selected to tailor analyses for specific studies. ${ }^{28}$

Table 2. Interview Participation Rate by Clinic Role

\begin{tabular}{lccc}
\hline Clinic role & Invited & Interviewed & Participation \\
\hline Leadership & 5 & 5 & $100 \%$ \\
MD & 6 & 2 & $33 \%$ \\
Resident & 9 & 2 & $22 \%$ \\
RN & 9 & 7 & $78 \%$ \\
LPN & 7 & 4 & $57 \%$ \\
Clerk & 10 & 2 & $20 \%$ \\
Total & 46 & 22 & $47 \%$ \\
\hline
\end{tabular}

In the process of writing and presenting detailed summaries of our data for quality improvement (QI) work, we identified fifteen CFIR constructs that aligned with emerging themes involving contextual influences on implementation. During further QI work and informal discussions with leadership, it became clear that the lack of foundational resources needed to form teamlets able to conduct practice redesign (e.g., develop a pre-visit planning process) was fundamental to the clinic's experience with early PACT implementation. The PACT schematic (Fig. 1) issued by VHA roughly one year after PACT was funded indeed suggested that practice design required foundational components to be in place. Therefore, we chose to focus our data analysis on challenges to implementing foundational resource components - staff, space, community, and technology. We narrowed our set of CFIR constructs to five. Three constructs, Available Resources, Networks and Communications, and Access to Knowledge and Information, mapped to the foundational resource components (Table 3). Two additional constructs, Complexity and Compatibility, which did not map to the foundation, were included due to their relevance to early implementation.

All four analysts used constant comparison techniques ${ }^{29}$ to refine and operationalize construct definitions and ensure a common understanding of constructs. Two analysts each coded more than $15 \%$ of the same transcripts independently, to ensure coding consistency. These analyst pairs initially met weekly to compare codes and resolve any discrepancies through consensus. ${ }^{30}$ Analysts then coded the remaining transcripts independently. We used NVivo ${ }^{31}$ to generate code reports for each of the five constructs, from which memos were written. Team analysis and discussion of memos led to our findings.

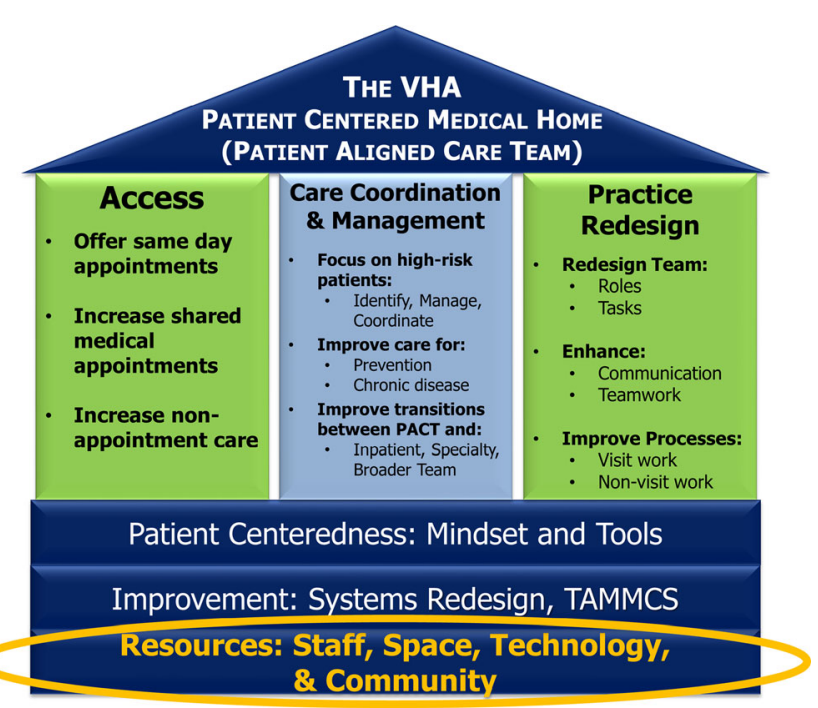

Figure 1. Veterans Health Administration Patient Aligned Care Teams schematic. 
Table 3. Guiding Frameworks and Study Findings

\begin{tabular}{|c|c|c|}
\hline $\begin{array}{l}\text { CFIR constructs and PACT } \\
\text { model foundation elements }\end{array}$ & CFIR construct definitions & Findings \\
\hline CFIR: Complexity & $\begin{array}{l}\text { Perceived difficulty of implementation, reflected by } \\
\text { duration, scope, radicalness, disruptiveness, } \\
\text { centrality, and intricacy and number of steps required } \\
\text { to implement. }\end{array}$ & $\begin{array}{l}\text { Leadership described PACT implementation as } \\
\text { "phenomenally complicated," and realized that it } \\
\text { required fundamental changes in clinic structure, work } \\
\text { processes, and physician and staff roles and identities. }\end{array}$ \\
\hline CFIR: Compatibility & $\begin{array}{l}\text { How the intervention fits with existing systems and } \\
\text { workflows. }\end{array}$ & $\begin{array}{l}\text { Although the clinic had some advantages associated } \\
\text { with large practices (e.g., EMR, advanced case } \\
\text { management), the existing large team structure and } \\
\text { having multiple part-time PCPs and residents } \\
\text { decreased its compatibility with the PACT teamlet } \\
\text { model. }\end{array}$ \\
\hline $\begin{array}{l}\text { CFIR: Available Resources } \\
\text { PACT Model: Staff and Space }\end{array}$ & $\begin{array}{l}\text { The level of resources dedicated for implementation } \\
\text { and on-going operations. }\end{array}$ & $\begin{array}{l}\text { Short-staffing, due to a low initial staffing ratio, a slow } \\
\text { and resource-intensive hiring process, and high } \\
\text { turnover, undermined development of teamlet working } \\
\text { relationships. } \\
\text { A lack of space in clinic, combined with the } \\
\text { complexities of scheduling part-time PCP and resident } \\
\text { clinics, made co-location of teamlet members difficult, } \\
\text { and affected how easily and efficiently team members } \\
\text { could communicate. }\end{array}$ \\
\hline $\begin{array}{l}\text { CFIR: Networks \& } \\
\text { Communications } \\
\text { PACT Model: Community } \\
\text { and Technology }\end{array}$ & $\begin{array}{l}\text { The nature and quality of social networks and formal } \\
\text { and informal communications within an organization. }\end{array}$ & $\begin{array}{l}\text { Communication among teamlet members was hampered } \\
\text { by lack of co-location in clinic and difficulty } \\
\text { communicating with residents when they were not in } \\
\text { clinic. Technological solutions were particularly } \\
\text { important under these circumstances. }\end{array}$ \\
\hline $\begin{array}{l}\text { CFIR: Access to Knowledge } \\
\text { and Information } \\
\text { PACT Model: Staff }\end{array}$ & $\begin{array}{l}\text { Ease of access to digestible information and } \\
\text { knowledge about the intervention and how to } \\
\text { incorporate it into work tasks. }\end{array}$ & $\begin{array}{l}\text { Because part-time PCPs and residents were in clinic so } \\
\text { infrequently and at varying times, and because of } \\
\text { delays in teamlet formation, the opportunities to } \\
\text { educate and reinforce PACT principles were limited. }\end{array}$ \\
\hline
\end{tabular}

\section{FINDINGS}

Table 3 provides a summary of findings mapped to the five CFIR constructs and four foundation components. We present them here in detail.

\section{Complexity}

Leadership described PACT implementation as "phenomenally complicated," and realized that it required fundamental changes in clinic structure, work processes, and physician and staff roles and identities. Largely due to understaffing, they initially focused primarily on redesigning clinic processes and staff roles without teamlets as a pathway to meeting PACT goals. Leadership's experience, and VHA's introduction of the PACT schematic, influenced them to shift their focus to addressing deficits in foundational resources. A member of the leadership team described their experience attempting to implement a new program to help RNCMs better manage high-risk patients:

"If [the] foundation isn't built, then you can't have anything on top of [the] foundation... and expect it to be functional... it's a slow, very challenging and frustrating process." Leadership 1

Although the clinic had several PCMH elements in place, such as clinical pharmacists and social workers on teams, advanced nurse case management and an EMR, achieving
PACT transformation could likely not occur without teamlets.

\section{Compatibility: Getting from Teams to Teamlets}

The PACT model was, in many ways, incompatible with the pre-existing care delivery system. At PACT's inception, the clinic was organized into four large teams, each with an average of 15 PCPs and residents, two RNCMs, two LPNs, and one clerk. Each team was responsible for about 3,500 patients. These teams had to be reorganized into 16 teamlets, each responsible for $800-1,200$ patients, with an average of 3.5 PCPs and residents on each teamlet. To meet the mandated 3:1 staff to provider ratio, non-physician staff needed to more than double, as the clinic started implementation with the lowest staffing ratio in its region. Having multiple part-time PCPs and residents fill the single FTE provider role on each teamlet complicated the transition:

"Because we're a tertiary site, that's been a huge issue for us...every other site in our health care system has full-time providers ...you're linking up one nurse, one LPN with one doc, very different than linking up with...up to five to six docs that are on different half days...it's a very different model..." Leadership 2 
A major challenge was distributing provider and resident clinics, and therefore workload for other teamlet members, evenly across the week to ensure an adequate ratio of staff to providers on any given day:

"... since there are three and a half docs per teamlet...they may have two and sometimes even three doctors on occasion who may be in the clinic at the same time, and so it shifts the workload for the teamlet." Leadership 1

It wasn't until May 2011, roughly 1 year into implementation, that physicians and staff were assigned to teamlets, though they were not fully staffed. Although some practice change began (e.g., an LPN checked in patients of providers on her teamlet, if possible), it wasn't until roughly January 2013 (almost a year past the end of our study period), that teamlets were able to work together on practice redesign.

\section{Available Resources: Staff}

Leadership's ability to hire the large number of new staff required to fully staff teamlets was affected by several factors. First, the hiring process, especially for nurses, was slow and resource-intensive: "We've hired [a lot of] people this year. So there has been a lot of interviewing and that's working with HR. That's taken ... a huge amount of time..." Leadership 2

High nurse turnover also contributed to the shortage, with some experienced nurses transferring to other units and some newly-hired nurses leaving because they were overwhelmed by working in this uncertain, rapidly changing primary care setting:

“...we all kind of think the concept's good. It's just how they execute it that's going to be the big thing. Because like right now, pretty much the RNs are... really in an uproar...we have four [out of twelve]... leaving." Leadership 3

The shortage in staff affected workload and required staff to cover vacancies in other teamlets, undermining development of teamlet working relationships vital for PACT work:

"You need to be involved with just your teamlet only... the nurse tells [the doctor], 'You have a cancellation... and so and so needs a pap smear and so and so needs blood work.' We don't do that. We don't even know who they're seeing...it's unorganized." LPN 1

\section{Available Resources: Space}

Leadership had to secure enough contiguous and wellconfigured space to accommodate a growing staff and co-locate teamlet members so they could communicate face-to-face. One leader described this challenge as "scavenging" for space, which required taking advantage of opportunities presented when other services relocated or moved to newly constructed space. A lack of space in clinic, combined with the need to schedule a varying roster of part-time PCPs and residents each day, made co-location of teamlet members a difficult puzzle to solve. The lack of co-location affected how easily and efficiently teamlet members communicated.

"In some instances, we have so many docs from a given team in clinic that you may be 200, 300 feet from your nurse so that you know, that direct sameday communication where you can just walk out of an office two feet away...to have a discussion about a patient care need is somewhat limited right now." Leadership 4

Despite the lack of space, staff recognized and looked forward to the benefits of co-location. One LPN observed that co-locating her teamlet would facilitate patient-centered care by bringing care to the patient:

"I think [being co-located will] help the Veterans move through the clinic a little quicker... now they've got to...have a seat, then we come back out and call them...the doctor could...just come and say... [this patient] needs an EKG...'. I could just come right to the room...do the EKG and then let them continue on." LPN 2

\section{Networks and Communications}

Space issues introduced significant communication challenges that leadership tried to address. For example, because staff did not have stable space or phone numbers, portable phones and instant messaging (IM) were implemented. Though dead zones within the clinic prevented reliable connections via portable phones, IM was used successfully both in clinic and for communication between staff and part-time PCPs who were on-site but not in the primary care clinic.

"...it is great to use with the [part-time] docs, because they are not always in clinic but elsewhere in the hospital and some say they do not like being paged." RN meeting field notes

Communication with residents, who were off-site most of the time, was particularly challenging, as an RNCM described:

"[the providers are]...very responsive... The biggest group... we have trouble communicating with are the residents...because they're not here very much and have other obligations." RNCM 1 
Although the EMR and VHA email were relied on heavily as communication tools, particularly for communication with nurses, checking them daily was a challenge for residents:

“...when a patient makes a phone call, they expect an answer within half a day...it doesn't happen... because I'll check my [EMR for alerts] once every 3 days...the biggest barrier is...email...I'm doing a [remote access] desktop but...I can't get it at home." Resident 1

\section{Access to Knowledge and Information} Educating Residents and Part-Time Physicians. Because part-time PCPs and residents were in clinic so infrequently and at varying times, the opportunities to disseminate and reinforce PACT principles were limited. PACT information for part-time PCPs and residents was communicated primarily at staff meetings. But many were unable to attend due to other responsibilities:

"...there are meetings between our clinic [mentors] and staff on a semi-regular basis. They usually occur...when we have to be finishing up seeing our patients and...leaving for other responsibilities.... even though residents are welcome to go to those meetings... we don't...go on any regular basis." Resident 2

Since coordinating meeting times with clinic hours was difficult, leadership hoped that PACT information would "filter down" to residents. However, largely because teamlets were not yet fully implemented, residents were not wellinformed about what PACT was and what their role would be in this new model of care. The education residents received from mentors pertained primarily to clinical care, not PACT processes. Mentors were ill-equipped to provide PACT education to residents because many were, themselves, in clinic only part-time and had limited exposure to PACT:

"...the model was built to educate residents on the clinical practice of medicine...managing heart failure, lung disease, etcetera... what [mentors] have a harder time doing is educating them on practice management, how do you...get involved in access for your patients, how do you actively identify patients who use resources...they don't live those things themselves." Leadership 4

An RNCM perceived that some residents and part-time providers were not fully engaged in clinic activities, and hence, PACT: "There's so many providers who spend so little time here and they just want to...get their work done, move on..." RNCM 2
Educating Staff. There were also barriers to training and educating staff, largely due to delays in forming teamlets, and exacerbated by the hiring of multiple staff members and high RNCM and LPN turnover. Leadership recognized the need for a designated PACT nurse trainer who could convey PACT principles and process changes consistently to all new staff. However, many of the established RNCMs had not been similarly trained. Therefore, new hires freshly oriented to PACT processes were told by colleagues that the way they were providing care conflicted with the status quo:

RN educator- "I'm training them for the PACT model and it's getting confusing when they come into the clinic and are told that's not the way we do things." RNCM meeting field notes

Not only were new hires required to learn PACT, but many came from inpatient or surgery units and were not experienced with working in a primary care setting:

"...they need to hire nurses that have a good medical background...I'm not saying they can't hire anybody...without a strong background [in primary care] because they can, but not in a time where they're making so many changes." RNCM 3

\section{DISCUSSION}

The PCMH model is complex and transformational, requiring substantial changes in clinic structure and work processes, as well as professional roles and identities. ${ }^{19}$ In PACT, teamlets, with a mandated 3:1 staffing ratio, play a central part in the practice redesign needed to accomplish a wide range of PACT goals, thus making them especially critical to successful implementation. PACT's particular specification and centrality of teamlets distinguishes it from other PCMH models, which define teams and their scope of responsibilities variably. ${ }^{8,24,32-34}$ However, we found that, in a large VHA academic medical center clinic, establishing the foundation (e.g., sufficient staff to form teamlets able to do practice redesign) is an essential first step in being able to implement the PACT model, and eventually meet PACT goals. This finding is unique, as previous studies have assessed the presence of PCMH elements to measure readiness for implementation or implementation progress, ${ }^{11,13-15,33}$ described factors that affect readiness and capacity for change in a wide range of primarily small, nonVHA settings, ${ }^{16,17,19,23}$ or assessed changes in roles and work processes to understand the functioning of alreadyformed PACT teamlets. ${ }^{20,21}$

Staffing shortages resulted from a slow and resourceintensive hiring process and high turnover, and undermined development of teamlet working relationships. This finding 
is consistent with previous studies which found that inadequate team staffing and an influx of new staff makes it difficult to establish relationships, reallocate roles and responsibilities, and develop new work processes. ${ }^{12,20,21}$ Staff shortage and barriers to hiring in the face of a growing patient population appear to be system-wide challenges in VHA. ${ }^{5}$ Recruiting and retaining staff is especially challenging in a stressful, rapidly changing environment. ${ }^{35}$ Providing a stimulating learning environment and clearly linking changes in clinic processes with a larger vision ${ }^{23}$ are two potential mitigating strategies. Clinic leaders must take existing staffing levels, projected patient growth, and the nature of the hiring process into account when determining the resources and time needed to achieve adequate staffing.

Inadequate space and communication gaps were closely related. Lack of space, along with the complications of constructing daily schedules with a changing roster of parttime PCPs and residents, were barriers to co-locating teamlet members, and, therefore, hampered their ability to communicate easily and quickly during the day. Our findings are consistent with Oandasan et al., who found that space has a substantial effect on "the quantity and quality of inter-professional communication and collaboration in primary health care." ${ }^{36} \mathrm{We}$ found that technology that allows for real-time communication in clinic, such as IM, was especially important in these circumstances. These issues highlight the need, particularly in large complex settings, to carefully consider how to best use space and technology to foster teamlet communication.

Communication with residents when they were off-site was hampered by their difficulty accessing communication systems. Residents' academic and VHA affiliations required them to use two non-integrated information technology (IT) systems, creating a barrier to communicating with their teamlet. Attention to modes of communication with residents is essential to providing continuity of care to patients.

Educating providers, residents, and staff in the PACT model was challenging. Having a "shared vision" of PCMH principles is fundamental to successful implementation, and must be communicated early and consistently. ${ }^{19}$ Our findings confirm and extend Nutting's finding that, as opposed to small practices in which an engaged physician leader can more easily motivate change, doing so is more difficult in complex settings; in this case, a large clinic with part-time providers and residents with competing priorities and limited clinic hours, and an influx of new staff, some of whom were new to primary care. ${ }^{19}$ Our finding that it was more difficult to engage providers with limited clinic hours is consistent with previous studies, ${ }^{19,23}$ and, crucially, without functioning teamlets, there was little opportunity for experiential learning. Staff had some vision of and enthusiasm for the PACT model, but were not functioning in teamlets until more than a year and a half after our study period ended.
Investment in time and training to develop well-functioning teams is an important strategy to address these gaps. $^{24,37}$ In early 2013, clinical leadership initiated a coaching model in which they and designated PCPs meet regularly with each teamlet on particular work processes designed to meet PACT goals (e.g., panel management to increase access). Including part-time providers and residents in this training will be crucial to success. The VHA Primary Care Program Office and the Office of Academic Affiliations have expressed a strong commitment to the medical home model and healthcare team member training.

This study has limitations. It was conducted at one VHA academic medical center, and, although we believe our findings provide valuable lessons, we are limited in our ability to transfer these findings to other like settings, particularly to non-VHA sites implementing other PCMH models. Multi-site studies that test and extend our findings would be valuable. Because the research team was working with leadership on quality improvement activities, staff may have been reluctant to share negative experiences and attitudes, despite assurances of confidentiality. However, we believe this potential effect was mitigated by triangulation of detailed data from multiple data collection techniques and multiple research participants in each clinic role. Another limitation is the small number of PCP and resident participants, which was due to recruiting difficulties and a mid-study shift of limited resources to target RNCMs and LPNs, who had greater knowledge and experience of PACT implementation.

Our use of the template organizing style, using CFIR constructs as codes, may have biased our attention to particular aspects of implementation at the expense of others, or limited our ability to see patterns in the data that would enrich our understanding of challenges faced by the clinic. However, CFIR sensitized us to consider how both PACT's complexity and the clinic's starting point affected implementation. It also led us to the insight that staff training (access to Knowledge and Information) was a foundational requirement, though it is not included explicitly in the PACT schematic. Finally, our focus was on identifying and describing the fundamental influences on implementation, not on changes in work processes. We are currently conducting a follow-up study that will allow us to compare different periods in PACT implementation, and to describe strategies that VHA PACTs are using to integrate trainees and part-time providers into teamlets.

Large academic medical centers face special challenges in implementing the medical home model. The presence of part-time providers and residents and large size make their existing care model less compatible with the PCMH model than settings in which PCMH was initially conceived and implemented. In an era of increasing emphasis on patientcentered care and Accountable Care Organizations, ${ }^{38}$ we believe that our findings will be of value to others within and beyond VHA, to both improve patient care and train 
clinicians to move from a physician-centric to a patientcentered multi-disciplinary team-based model. ${ }^{24}$ Although the time it took to build the foundation was considerable, it has proven essential. As of this writing, the clinic has 20 functioning teamlets and is beginning to experience more rapid uptake of the work processes needed to provide true patient-aligned care.

Acknowledgements: The authors would like to thank the clinical leaders, physicians, and staff who participated in this study and the members of the VISN 11 PRIISM Demonstration Laboratory.

Contributors: Thanks also to Laura Damschroder for her assistance in editing this manuscript, and to Lauren Weston for administrative and research assistance.

Funders: This work was undertaken as part of the Veterans Administration's PACT Demonstration Laboratory initiative, supporting and evaluating VA's transition to a patient-centered medical home. Funding for the PACT Demonstration Laboratory initiative is provided by the VA Office of Patient Care Services.

Prior presentations: We presented an earlier version of the manuscript as a poster at the Society of General Internal Medicine $36^{\text {th }}$ Annual Meeting in Denver, Colorado on April 26, 2013, and at the Academy Health Annual Research Meeting in Baltimore, Maryland on June 23, 2013.

Conflict of Interest: The authors declare that they do not have a conflict of interest.

Corresponding Author: Jane Forman, ScD, MHS; PACT Research Inspiring Innovations and Self-Management (PRIISM) Demonstration Laboratory, Center for Clinical Management Research, VA Ann Arbor Healthcare System, Ann Arbor, MI, USA (e-mail: Jane.Forman@va.gov).

\section{REFERENCES}

1. Department of Veterans Affairs, Patient Centered Primary Care Implementation Work Group [Internet]. Patient centered medical home model concept paper [accessed 2013 October 7]. Available from: http:// www.va.gov/PRIMARYCARE/PACT/index.asp.

2. AHRQ. Federal Patient Centered Medical Home (PCMH) collaborative catalogue of PCMH activities. Rockville: Agency for Healthcare Research and Quality; 2012.

3. Davis K, Abrams M, Stremikis K. How the Affordable Care Act will strengthen the nation's primary care foundation. J Gen Intern Med. 2011;26(10):1201-3.

4. Yano EM, Simon BF, Lanto AB, Rubenstein LV. The evolution of changes in primary care delivery underlying the Veterans Health Administration's quality transformation. Am J Public Health. 2007:97:2151-9.

5. Rosland AM, Nelson K, Sun H, Dolan ED, Maynard C, Bryson C, Stark R, Shear JM, Kerr E, Fihn SD, Schectman G. The patient-centered medical home in the Veterans Health Administration. Am J Manag Care. 2013;19(7):e263-72.

6. Ghorob A, Bodenheimer T. Sharing the care to improve access to primary care. N Engl J Med. 2012;366(21):1955-7.

7. Chesluk BJ, Holmboe ES. How teams work-or don't-in primary care: a field study of internal medicine practices. Health Aff. 2010;29(5):874-9.

8. Bodenheimer T, Laing BY. The teamlet model of primary care. Ann Fam Med. 2007;5(5):457-61.

9. Chang A, Bowen JL, Buranosky RA, Ghosh N, Rosenblum MJ, Thompson S. Transforming primary care training-patient-centered medical home entrustable professional activities for internal medicine residents. J Gen Intern Med. 2012;28(6):801-9.

10. Chang BK. GME enhancement: expansion and educational innovation in VA residency programs. Acad Intern Med Insight. 2009;7(2):6,13.
11. Rittenhouse DR, Casalino LP, Gillies RR, Shortell SM, Lau B. Measuring the medical home infrastructure in large medical groups. Health Aff. 2008;27(5):1246-58.

12. Coleman K, Phillips K. Providing underserved patients with medical homes: Assessing the readiness of safety-net health centers. Issue Brief (Commonw Fund). 2010;85:1-14.

13. Hollingsworth JM, Saint S, Sakshaug JW, Hayward RA, Zhang L, Miller DC. Physician practices and readiness for medical home reforms: Policy, pitfalls, and possibilities. Health Serv Res. 2012;47(1 Pt 2):486-508.

14. Friedberg MW, Safran DG, Coltin KL, Dresser M, Schneider EC. Readiness for the patient-centered medical home: Structural capabilities of Massachusetts primary care practices. J Gen Intern Med. 2008;24(2):162-9.

15. Rittenhouse DR, Casalino LP, Shortell SM, McClellan SR, Gillies RR, Alexander JA, Drum ML. Small and medium-size physician practices use few patient-centered medical home processes. Health Aff. 2011;30(8):1575-84.

16. Bitton A, Schwartz GR, Stewart EE, Henderson DE, Keohane CA, Bates DW, Schiff GD. Off the hamster wheel? Qualitative evaluation of a payment-linked patient-centered medical home (PCMH) pilot. Milbank $\mathrm{Q}$. 2012;90(3):484-515.

17. Wise CG, Alexander JA, Green LA, Cohen GR, Koster CR. Journey toward a patient-centered medical home: Readiness for change in primary care practices. Milbank Q. 2011;89(3):399-424.

18. Arar NH, Noel PH, Leykum L, Zeber JE, Romero R, Parchman ML. Implementing quality improvement in small, autonomous primary care practices: Implications for the patient centered medical home. Qual Prim Care. 2011;19(5):289-300.

19. Nutting PA, Crabtree BF, Miller WL, Stewart EE, Stange KC, Jaen CR. Journey to the patient-centered medical home: A qualitative analysis of the experiences of practices in the National Demonstration Project. Ann Fam Med. 2010;8(Suppl 1):S80-90.

20. True G, Butler AE, Lamparska BG, et al. Open access in the patientcentered medical home: Lessons from the Veterans Health Administration. J Gen Intern Med. 2012;28(4):539-45.

21. Solimeo SL, Hein M, Paez M, Ono S, Lampman M, Stewart GL. Medical homes require more than an EMR and aligned incentives. Am J Manag Care. 2013;19(2):132-40.

22. Day J, Scammon DL, Kim J, Sheets-Mervis A, Day R, TomoaiaCotisel A, et al. Quality, satisfaction, and financial efficiency associated with elements of primary care practice transformation: Preliminary findings. Ann Fam Med. 2013;11(Suppl 1):S50-9.

23. Fernald DH, Deaner N, O'Neill C, Jortberg BT, deGruy FV, Dickinson WP. Overcoming early barriers to PCMH practice improvement in family medicine residencies. Fam Med. 2011;43(7):503-9.

24. Markova T, Mateo M, Roth OM. Implementing teams in a patientcentered medical home residency practice: Lessons learned. J Am Board Fam Med. 2012;25:224-31.

25. Creswell JW. Qualitative inquiry and research design: Choosing among five approaches. Thousand Oaks: Sage; 2012:125-9.

26. Crabtree BF, Miller WL. Using codes and code manuals. In: Crabtree BF, Miller WL, William, eds. Doing qualitative research. 2nd ed. Thousand Oaks: Sage; 1999:163-77.

27. Damschroder LJ, Aron DC, Keith RE, Kirsh SR, Alexander JA, Lowery JC. Fostering implementation of health services research findings into practice: A consolidated framework for advancing implementation science. Implement Sci. 2009;4:50.

28. Damschroder LJ, Lowery JC. Evaluation of a large-scale weight management program using the consolidated framework for implementation research (CFIR). Implement Sci. 2013;8(1):51.

29. Glaser BG, Strauss AL. The discovery of grounded theory: Strategies for qualitative research. Chicago: Aldine Transaction; 1967:101-15.

30. Sandelowski M, Barroso J. Writing the proposal for a qualitative research methodology project. Qual Health Res. 2003;13(6):781-820.

31. NVivo qualitative data analysis software; QSR International Pty Ltd. Version 10, 2012.

32. Reid RJ, Coleman K, Johnson EA, Fishman PA, Hsu C, Soman MP. The Group Health Medical Home at year two: Cost savings, higher patient satisfaction, and less burnout for providers. Health Aff. 2010;29(5):835-43.

33. Nutting PA, Crabtree BF, Stewart EE, Miller WL, Palmer RF, Stange $\mathbf{K C}$, et al. Effect of facilitation on practice outcomes in the National Demonstration Project model of the patient-centered medical home. Ann Fam Med. 2010;8(Suppl 1):S33-44.

34. Agency for Healthcare Research and Quality [Internet]. Patient-centered medical home resources: Defining the PCMH [accessed 2013 October 7]. 
Available from: http://pcmh.ahrq.gov/portal/server.pt/community/ pcmh_home/1483/pcmh_defining_the_pcmh_v2

35. Shader K, Broom ME, Broome CD, West ME, Nash $M$. Factors influencing satisfaction and anticipated turnover for nurses in an academic medical center. J Nurs Adm. 2001;31(4):210-6.

36. Oandasan IF, Conn LG, Lingard L, et al. The impact of space and time on interprofessional teamwork in Canadian primary health care settings:
Implications for health care reform. Prim Health Care Res Dev. 2009; 10:151-62.

37. Belanger E, Rodriguez C. More than the sum of its parts? A qualitative research synthesis on multi-disciplinary primary care teams. J Interprof Care. 2008;22(6):587-97.

38. Fuchs VR. Current challenges to academic health centers. J Am Med Assoc. 2013;310(10):1021-2. 